\title{
ESTUDO PARA REABILITAÇÃO DE PATOLOGIAS NAS FACHADAS DE UMA EDIFICAÇÃ
}

\author{
L. G. MOURA, C. S. CALHEIROS \\ Universidade do Estado do Amazonas (UEA), Manaus - AM, Brasil.
}

\section{RESUMO}

O presente artigo analisou as patologias identificadas nas fachadas de uma edificação através de dois aspectos: inspeção predial, realizada com o auxílio de drone, e metodologia GUT. A partir da análise, pôde-se propor terapias adequadas para a reabilitação das principais patologias identificadas. Constatou-se através da inspeção predial que o estado de conservação da edificação era baixa e por meio do método GUT observou-se que as anomalias referentes ao descolamento ou desplacamento do revestimento cerâmico exibiam maior risco e apresentavam 31,5\% de incidência nas fachadas, sendo oriundas, principalmente, de falhas na execução. Paralelamente a isto, os casos de desplacamento apresentavam prioridade na resolução, visto que causavam danos tanto para a edificação quanto riscos para a vida dos transiuntes no local.

Palavras-chave: Fachadas; Manifestação Patológicas; Inspeção Predial; Método GUT; Reabilitação.

\begin{abstract}
The present article analyzed the pathologies identified in the facades of a building through two aspects: building inspection, performed with the aid of drone, and GUT methodology. From the analysis, appropriate therapies could be proposed for the rehabilitation of the main pathologies identified. The building inspection revealed that the state of conservation of the building was low and by means of the GUT method, it was observed that the anomalies related to the displacement of the ceramic tiles had a higher risk and had a $31.5 \%$ incidence on the façades, mainly due to failure in the execution. Parallel to this, the displacement cases presented priority in the resolution, since they caused damage to the building as well as risks to the life of pedestrians in the place.
\end{abstract}

Keywords: Facades, Building Inspection, Pathological Manifestations, GUT Method, Rehabilitation. 


\section{INTRODUÇÃO}

No Brasil, apesar dos avanços tecnológicos na construção civil, é evidente a numerosa quantidade de ocorrências patológicas nos sistemas construtivos e especificamente nas fachadas de edificações (SILVA, 2014).

As fachadas de uma edificação, por serem a primeira barreira contra as intempéries naturais, como a radiação solar, umidade e temperatura, precisam ser executadas considerando tanto a função estética, quanto a função de proteção que estas devem exercer. Assim sendo, este sistema construtivo deve propiciar uma proteção à ação direta de agentes agressivos, conforto e segurança aos usuários e trazer harmonia e equilíbrio entre a arquitetura e qualidade da construção (SANTOS, 2017; SILVA, 2009; BARBOSA, 2013).

Durante a vida útil de uma edificação é esperado que os sistemas construtivos estejam com o desempenho previsto em projeto, mas para isso, faz-se necessário que a etapa de construção tenha sido realizada de forma correta e posteriormente, na etapa de uso da edificação, as inspeções e manutenções periódicas sejam realizadas. Durante a etapa de uso poder-se-á realizar o processo de inspeção e conforme Tutitkian e Pacheco (2013), este processo deve viabilizar a identificação das manifestações patológicas conforme elas se apresentam, determinando se elas ocorrem de forma generalizada ou localizada e possibilitando ao profissional determinar as causas e/ou origens, os danos subsequentes e realizar uma proposta de reabilitação adequada.

A reabilitação de edificações é um mercado em crescimento e com alto potencial contudo, por dificuldades técnicas, políticas e financeiras, os profissionais da área da construção se desanimam em investir neste serviço (FERNANDES, 2013).

Não obstante a isto, atualmente se verificam diversas edificações recentes apresentando problemas de funcionamento e manifestações patológicas, gerando a necessidade precoce de intervenção e tanto a construtora, quanto as pessoas que adentram em um estabelecimento enfermo irão sofrer com os impactos das patologias, que podem ser tanto econômicos quanto sociais e considerando uma situação mais calamitosa, pode ocasionar graves acidentes. Desta forma, faz-se necessário investir nesta área. (FERNANDES, 2013; JÚNIOR, 2017).

Diante do exposto, o estudo de caso visa auxiliar na compreensão de melhores mecanismos para realização de vistorias nas fachadas das edificações, implementando uma tecnologia em ascensão nos dias atuais, o drone. E paralelamente a isto, utilizar a metodologia GUT, uma ferramenta técnica de gerenciamento de risco, para identificar as manifestações patológicas de maior gravidade, e diagnosticalas quanto suas possíveis causas e/ou origens para propor os procedimentos de reabilitação ideiais tanto para a edificação quanto para o proprietário e usuários desta.

\section{PROCEDIMENTO}

O projeto foi realizado em 5 etapas, compreendendo desde a inspeção das fachadas da edificação até a proposta de reabilitação das principais patologias manifestadas no local do estudo de caso, conforme se visualiza no fluxograma da Figura 1. Paralelamente a isto, as técnicas utilizadas para o estudo foram estruturadas de partes adaptadas da metodologia proposta pelo Instituto Brasileiro de Avaliações e Perícias de Engenharia (IBAPE) juntamente com a metodologia GUT, que foi a ferramenta escolhida como critério de avaliação das patologias. 


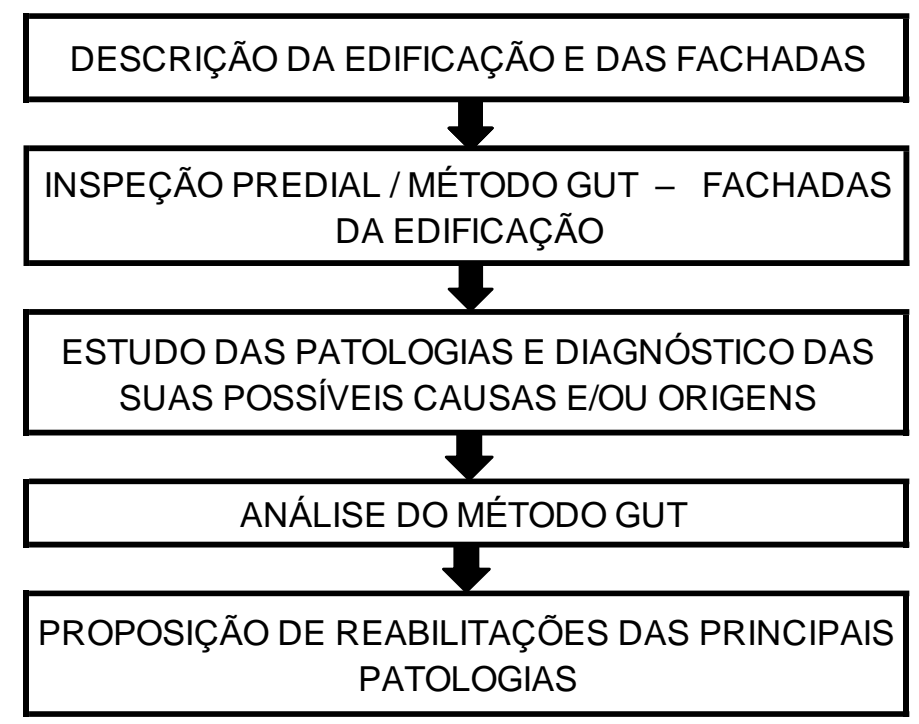

Figura 1. Etapas da metodologia proposta.

\subsection{Critérios de avaliação}

A metodologia GUT, desenvolvida na década de 1980 por Kepner e Tregoe, é uma ferramenta que busca minimizar os impactos identificados em um espaço através da priorização das ações e decisões que devem ser executadas. Para realizar tal objetivo, os problemas ou riscos potenciais devem ser identificados e, posteriormente, realiza-se a matriz GUT que gera um ranking de prioridades conforme os aspectos de gravidade $(\mathrm{G})$, urgência $(\mathrm{U})$ e tendência $(\mathrm{T})$ dos problemas progredirem (LUCINDA, 2010 ; TRISTÃO, 2011).

Conforme Marshall Junior et al. (2010), os três aspectos podem ser definidos como:

- Gravidade: refere-se ao custo, considerando os resultados, caso não seja realizada uma ação para solucionar o problema.

- Urgência: refere-se ao tempo necessário para evitar o dano, sabendo que quanto maior a urgência menor o prazo para saná-lo.

- Tendência: refere-se à tendência do problema aumentar com o decorrer do tempo, se a ação não for realizada.

Para utilização desta ferramenta no estudo de caso, foi preciso averiguar cada patologia sob a ótica da metodologia GUT, atribuindo, em uma escala crescente, um número inteiro entre 1 e 5, considerando o número 5 para os problemas de maior intensidade e o 1 para os de menor intensidade. Em seguida, multiplicou-se os valores obtidos em cada variável $(\mathrm{G}, \mathrm{U}, \mathrm{T})$ para a obtenção dos valores finais de cada problema (TRISTÃO, 2011).

Os valores finais dos fatores de riscos analisados formam o ranking de prioridades, no qual o maior valor designa o problema prioritário, seguido pelos outros problemas em ordem decrescente (BRASIL, 2013).

\subsection{Procedimentos metodológicos}

Inicialmente, na primeira etapa, realizou-se a revisão de literatura referente aos temas abordados, mediante a livros, artigos, normas, teses e monografias relacionadas as manifestações patológicas em fachadas de edificações. Posteriormente, nesta mesma etapa, foi-se realizado a descrição da edificação estudada e especificamente, das suas vedações externas.

A segunda etapa foi sumarizada pela inspeção predial juntamente com a metodologia GUT e para analisar minuciosamente as patologias manifestadas nas fachadas da edificação durante a inspeção predial, foi-se utilizado alguns equipamentos, como: máquina fotográfica, drone (veículo aéreo não tripulado), trena, paquímetro, escada, lupa, lanterna e fissurômetro. 
Neste caso, a utilização do drone (Mavic Pro) deveu-se a necessidade de analisar os pavimentos superiores com maior nitidez, eficácia e rapidez, garantindo maior segurança durante a realização das avaliações por não precisar aplicar o método tradicional (balancin, cadeira suspensa), e ao mesmo tempo mostrar os benefícios de se utilizar uma ferramenta inovadora e de alta tecnologia para efetuar avaliações prediais.

Simultaneamente à etapa de inspeção foi realizado o levantamento dos dados coletados, com o auxílio dos registros fotográficos e das informações sobre as anomalias visualizadas. De forma a organizar as informações obtidas pelo levantamento e analisar as manifestações patológicas encontradas, a terceira etapa, que foi a de estudo das patologias e diagnóstico das possíveis causas e/ou origens, foi efetuada seguindo sequencialmente, alguns itens, como: enumeração da patologia, registro fotográfico, descrição conforme a inspeção visual, tipos de anomalias identificadas e o diagnóstico das possíveis causas e/ou origens.

A etapa seguinte foi a análise do método GUT. Por meio deste método foi possível classificar as patologias encontradas conforme os aspectos de gravidade, urgência e tendência e, consequentemente, pôde-se realizar o ranking de prioridades para resolução das manifestações patológicas. Para a elaboração do ranking foi utilizado uma matriz GUT modificada, conforme o Quadro 1.

Quadro 1. Exemplo da Matriz GUT

\begin{tabular}{|c|c|c|c|c|c|c|}
\hline $\begin{array}{c}\text { MANIFESTAÇÃO } \\
\text { PATOLÓGICA }\end{array}$ & $\begin{array}{c}\text { LOCAL DE } \\
\text { INCIDÊNCIA }\end{array}$ & G & U & T & G X U X T & $\begin{array}{c}\text { RANKING DE } \\
\text { PRIORIDADES }\end{array}$ \\
\hline Manifestação Patológica 1 & $1^{\circ} / 2^{\circ} / 3^{\circ}$ PAV & & & & & \\
\hline Manifestação Patológica 2 & $\ldots$ & & & & & \\
\hline Manifestação Patológica 3 & $\ldots$ & & & & & \\
\hline ... & $\ldots$ & & & & & \\
\hline
\end{tabular}

Através da ordem de priorização de resolução das manifestações patológicas, pôde-se identificar as patologias mais críticas nas fachadas da edificação, sendo assim, as que necessitavam ser reabilitadas de forma imediata. Logo, na etapa de proposição da reabilitação, a quinta e última etapa da metodologia, as patologias com maior prioridade no ranking tiveram as suas possibilidades de terapêuticas expostas, seguido da elucidação dos procedimentos de execução para a reabilitação das mesmas.

\section{ESTUDO DE CASO}

\subsection{Caracterização tipológica da edificação}

Este estudo contempla a caracterização do sistema construtivo de uma edificação, enfatizando as vedações externas. A edificação analisada é de uso residencial multifamiliar, composta de três pavimentos, construída há aproximadamente 21 anos e está localizada na rua 7, número 20, bairro Cidade Nova, Manaus - AM. Na Figura 2 visualiza-se por meio do mapa a edificação. 


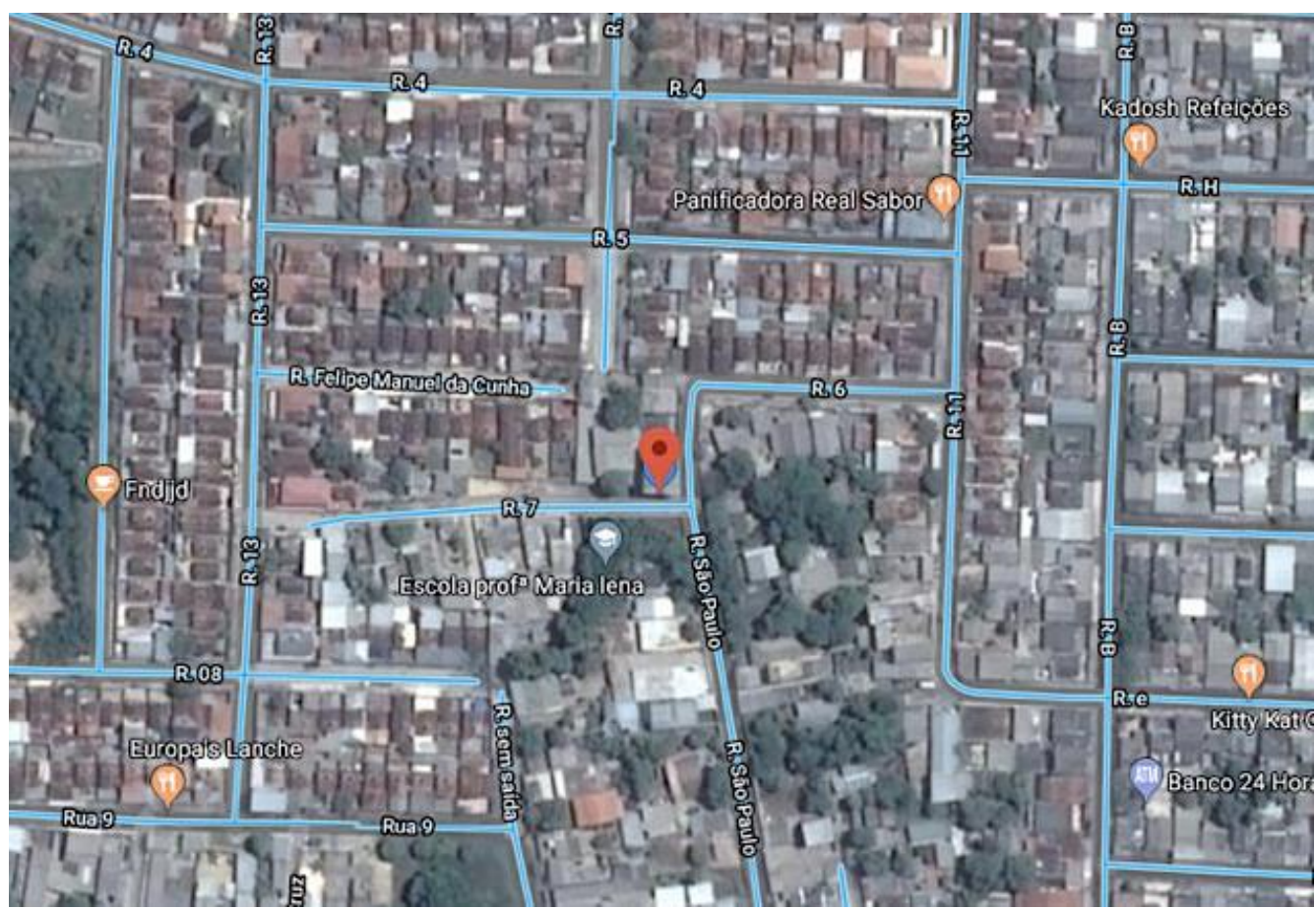

Figura 2. Mapa de localização da edificação. Fonte: GOOGLE MAPS (2018).

A edificação apresentou em sua composição estrutural o concreto armado e na vedação blocos cerâmicos furados, sendo as fachadas constituídas de quadro lados, que foram denominados conforme suas orientações solares. Os dois lados revestidos com cerâmica são os de acesso para o interior da edificação, podendo ser descritos como os lados frontais e denominados de fachada Sul e fachada Leste. As cerâmicas utilizadas nos lados frontais são de coloração verde e branco.

Os outros dois lados das fachadas são revestidos com tinta e denominados fachada Norte e fachada Oeste. A fachada Norte é revestida com tinta na coloração cinza e a fachada Oeste apresenta revestimento na coloração verde claro.

\subsection{Análise da edificação}

Conforme apresentado na metodologia, realizou-se a inspeção predial e esta foi classificada de nível 1, visto que a edificação estudada é composta de 3 pavimentos, sem elevador, e contém outras características constituintes do padrão baixo, conforme o IBRAENG (2015). Este nível é fundamentado em vistoria visual, logo, através deste foi possível detectar as anomalias visíveis nas fachadas da edificação.

\subsubsection{Fachada Sul}

A fachada frontal (Figura 3.a), orientada para o Sul, apresentou elevada incidência de descolamento e desplacamento de placas cerâmicas e também o desprendimento do material cimentício (argamassa), principalmente, no primeiro e segundo pavimento, conforme se visualiza na Figura 4, itens b, c e d, respectivamente. Paralelamente a esta manifestação patológica, observou-se a presença de bolores, nas primeiras fiadas da alvenaria do primeiro pavimento (Figura 4.a), advindos possivelmente por capilaridade da umidade presente na calçada.

No primeiro pavimento também observou-se fissuras verticais entre o pilar e a parede de alvenaria (Figura 3.b), devido às deformações diferenciais entre os diferentes sistemas, sendo que estas poderiam ser evitadas com a presença de telas entre as ligações do pilar (concreto armado) com a parede de alvenaria. Em menor escala, evidenciou-se a presença de sujidades nas placas cerâmicas próximas a cobertura da edificação (Figura 3.a), causada possivelmente pela presença de umidade descendente no local. Esta patologia pode ser oriunda da ausência de uma correta impermeabilização e manutenção na cobertura, ou ainda, por carência nos projetos dos sistema de calhas e condutores pluviais. 


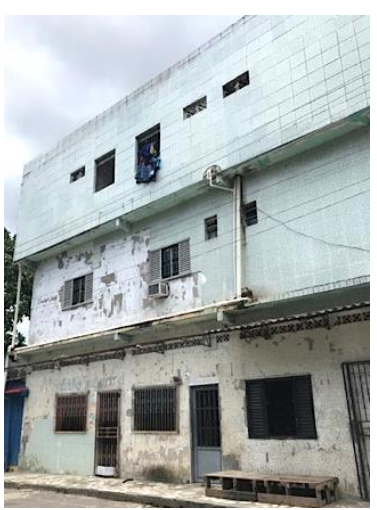

a)

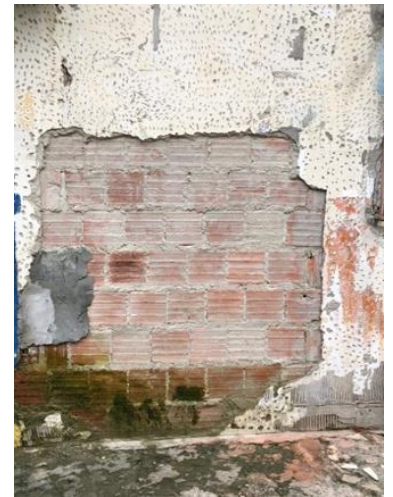

b)



c)

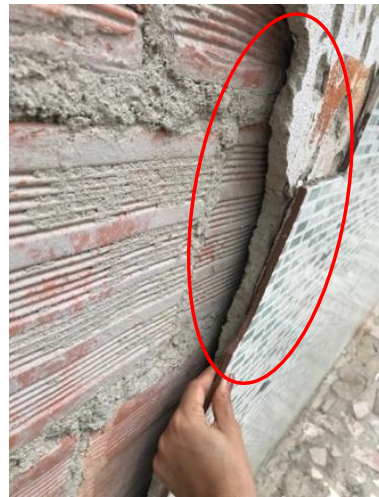

d)

Figura 3. Fachada Sul: a) Vista geral; b) Área com presença de fissura, bolor, desplacamento cerâmico; c) Detalhes do desplacamento cerâmico; d) Desprendimento do material cimentício.

Ainda nesta fachada foi observado a manifestação da patologia de corrosão nas esquadrias metálicas em contato com o material cimentício (Figura 4.b), demonstrando a falta de manutenção predial no local. Além desta patologia originada na etapa de utilização da edificação, foi identificado, também, falha na etapa de projeto através do sistema de tubulação da edificação. O mesmo se encontra aparente, sem proteção e despejando seu conteúdo em local inadequado, conforme se visualiza na Figura 3.a e na Figura 4.c. Como consequência desta falha juntamente com a falta de manutenção deste sistema, na Figura 4.d visualiza-se a presença de vegetação parasitária proveniente do vazamento de água da tubulação.

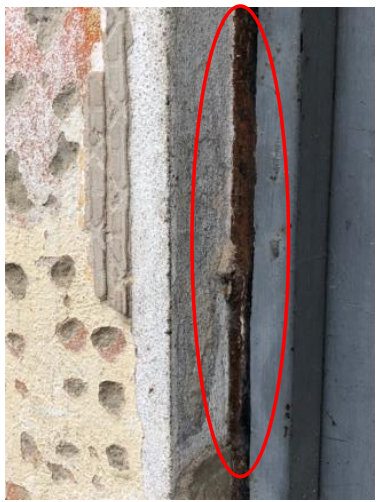

a)

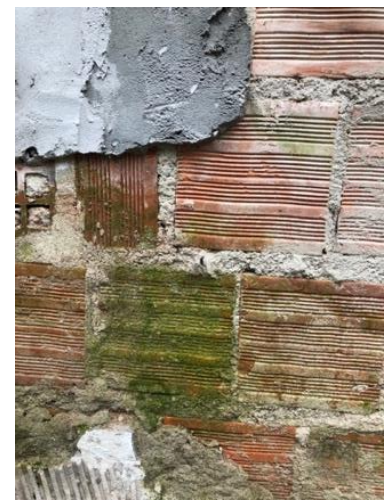

b)

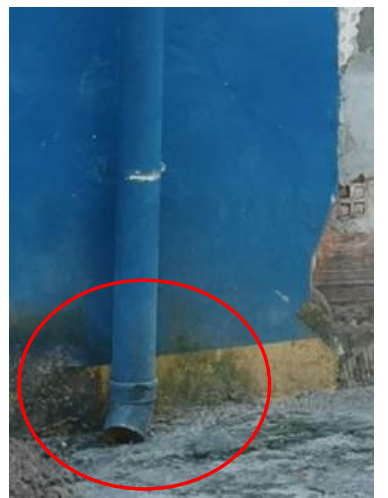

c)

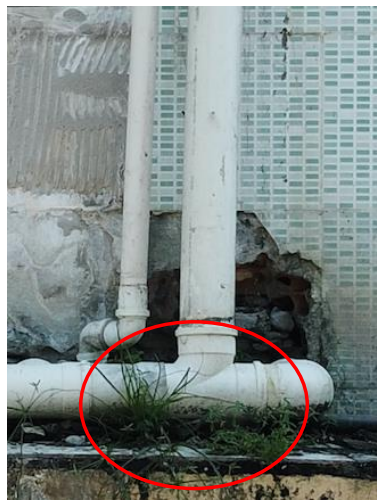

d)

Figura 4. Manifestações patológicas na Fachada Sul: a) Corrosão da esquadria metálica; b) Mancha de umidade e bolor; c) Local de despejo dos fluidos da tubulação; d) Vegetação parasitária e tubulação aparente.

\subsubsection{Fachada Leste}

A fachada Leste (Figura 5.a), foi considerada a com melhor aparência estética, visto que apresenta pouca incidência de manifestações patológicas quando comparada aos outros três lados de vedação externa. As patologias identificadas nesta fachada são semelhantes à fachada Sul, como as manchas por sujidades nas placas cerâmicas do terceiro pavimento e o desplacamento de placas cerâmicas. 


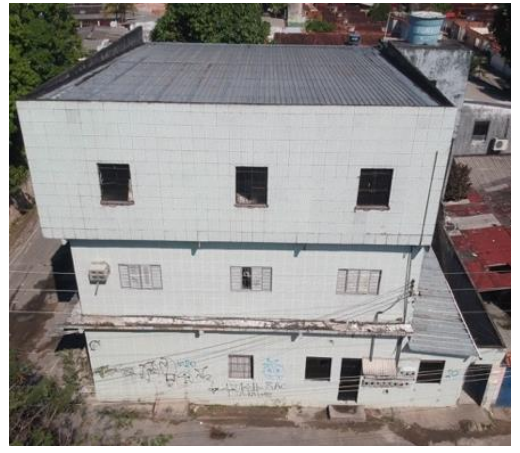

a)

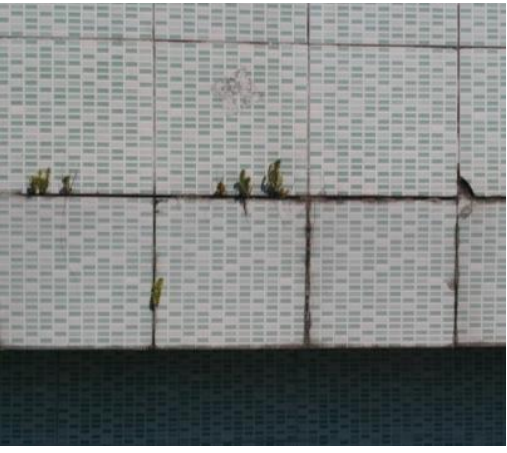

b)

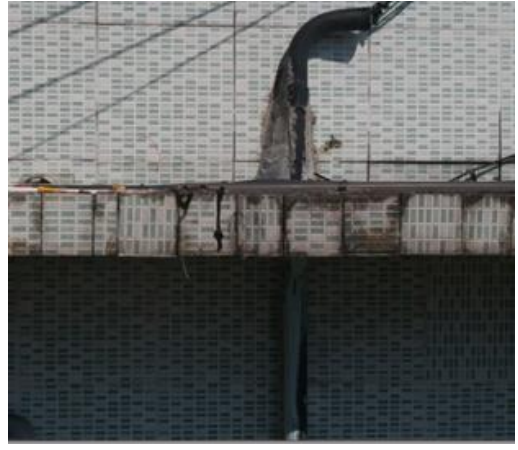

c)

Figura 5. Fachada Leste: a) Vista geral da fachada; b) Vegetação parasitária entre placas cerâmicas; c) Manchas de umidade, bolor e sujidade.

Ademais, notou-se a presença de vegetação parasitária entre placas cerâmicas do terceiro pavimento (Figura 5.b), especificamente no local onde deveria conter o rejunte, e ao redor da vegetação parasitária e em outros pontos da fachada visualizou-se sujidade e microfissuras no rejunte. A vegetação parasitária evidencia a presença de umidade no local, o perigo de um futuro desplacamento das placas cerâmicas e a necessidade de manutenção predial, visto que a manutenção poderia ter evitado estas patologias. Não obstante, durante a inspeção predial analisou-se as placas cerâmicas na marquise do primeiro pavimento (Figura 5.c), estas manifestaram sintomas através de manchas de umidade e bolor, juntamente com sujidades, ratificando a falta de manutenção na edificação.

\subsubsection{Fachada Norte}

A fachada Norte é revestida com argamassa e tinta na coloração cinza, todavia, por consequência da elevada incidência de sujidade e manchas de bolor nas paredes desta fachada, a pintura se torna predominantemente escura, em tonalidade preta, conforme se visualiza na Figura 6.a. Além desta patologia, observou-se a manifestação de fissuras de diversas formas, como as fissuras mapeadas (Figura 6.b), oriundas da retração da argamassa e as fissuras causadas por movimentações higroscópicas, conforme se visualiza na Figura 6.c.

Na Figura 6.c, é possível visualizar que a alvenaria da mesma fiada em que estava situada a fissura por movimentação higroscópica, apresentou-se danificada e com a presença de eflorescência. Paralelamente a isto, nesta mesma figura pôde-se constatar a deterioração da esquadria metálica na janela do segundo pavimento, apresentando fissuras e destacamento do revestimento.

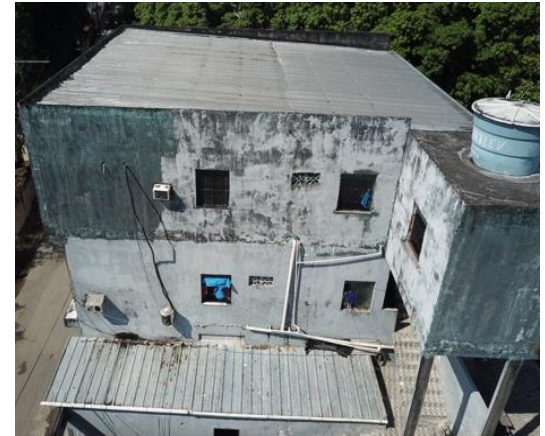

a)

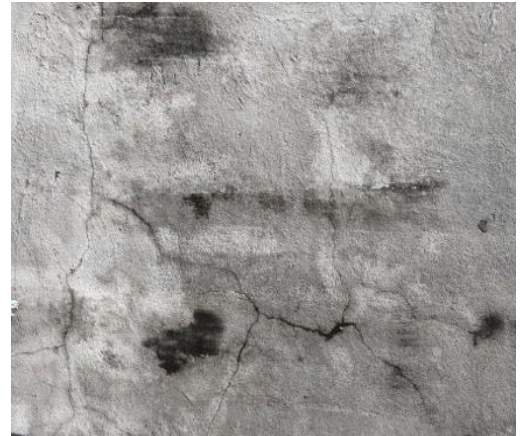

b)

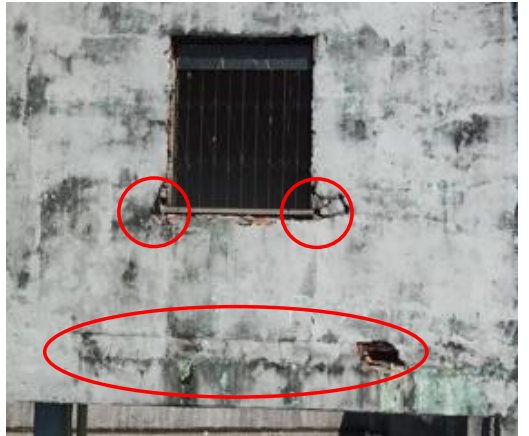

c)

Figura 6. Fachada Norte: a) Vista geral da fachada; b) Fissuras mapeadas; c) Fissuras por movimentação higroscópica, deterioração da esquadria metálica e manchas de eflorescência.

Nesta vedação externa ainda observou-se a deterioração do suporte para ar condicionado, com a presença de manchas de umidade e bolores (Figura 7.a), por consequência da falta do dreno de ar condicionado no local, desta forma os líquidos são lançados diretamente no revestimento da parede. Paralelamente a isto, observou-se falhas nas etapas de projeto e execução do sistema hidráulico da 
fachada, conforme se visualiza na Figura 7.b. Nesta figura destacou-se a presença de manchas de bolor e eflorescência, pelo despejo inadequado dos fluidos.

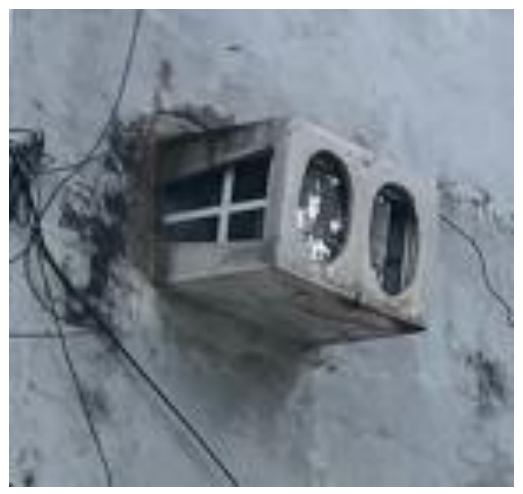

a)

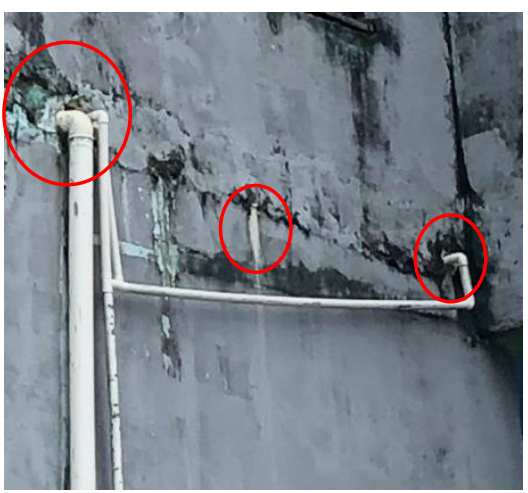

b)

Figura 7. Manifestações patológicas na Fachada Norte: a) Suporte de ar condicionado; b) Sistema hidráulico exposto e manchas de eflorescência e bolor.

\subsubsection{Fachada Oeste}

A fachada lateral, orientada para o Oeste (Figura 8.a), é constituída, predominantemente, de paredes externas na tonalidade verde-claro e revestida com argamassa. Com exceção das paredes externas do primeiro pavimento que está em contato direto com o imóvel ao lado, não apresentando patologias e sendo revestido com argamassa e tinta na coloração branca.

Em relação ao segundo e terceiro pavimento, pôde-se identificar diversas patologias oriundas da presença de água indevida no local, por consequência de erros nos projetos ou execução da obra. A parede externa abaixo da caixa d'água apresenta uma alta incidência de bolores (Figura 8.b), por consequência de erros durante a execução e utilização da obra, visto que não foi realizada a adequada impermeabilização na área.

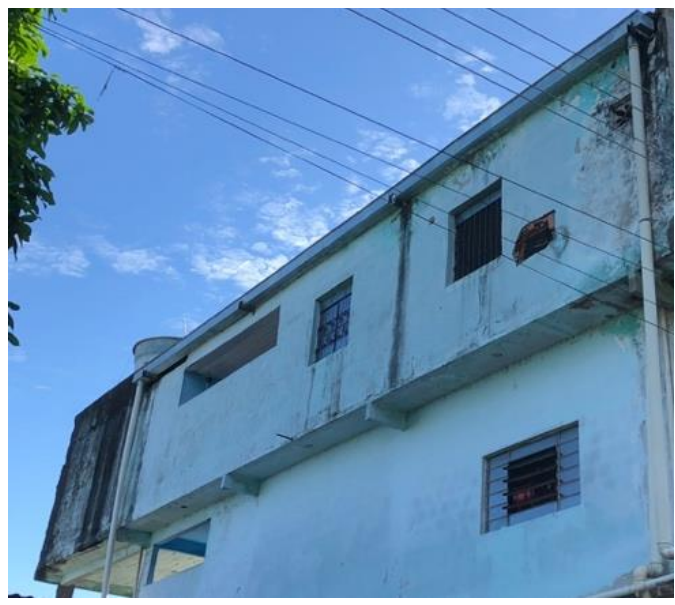

a)



b)

Figura 8. Fachada Oeste: a) Vista geral da fachada; b) Bolor na parede lateral à caixa d'água.

Outras áreas, principalmente no terceiro pavimento, conforme a Figura 9, apresentam manchas de umidade, descoloração da tinta aplicada, e a presença de bolores, oriundas da má execução do sistema de calhas, condutores pluviais e a falta de manutenção no local.

Além destas patologias, na Figura 9.a, pode-se observar os blocos cerâmicos através do revestimento de tinta, o que foi possivelmente originado pelo tempo de cura insuficiente do revestimento. Nesta mesma figura foi observado fissuras horizontais localizadas na amarração entre laje e blocos cerâmicos do terceiro pavimento. 


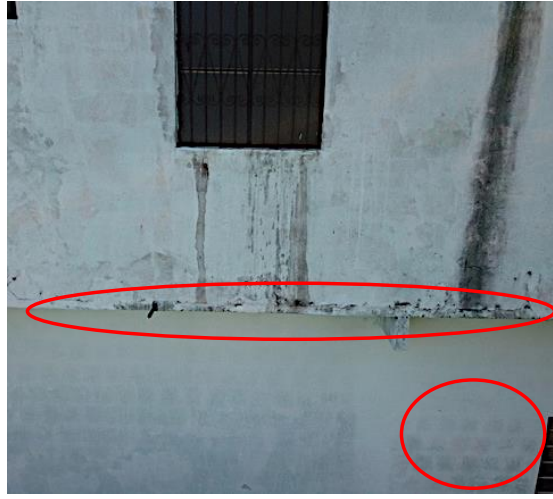

a)

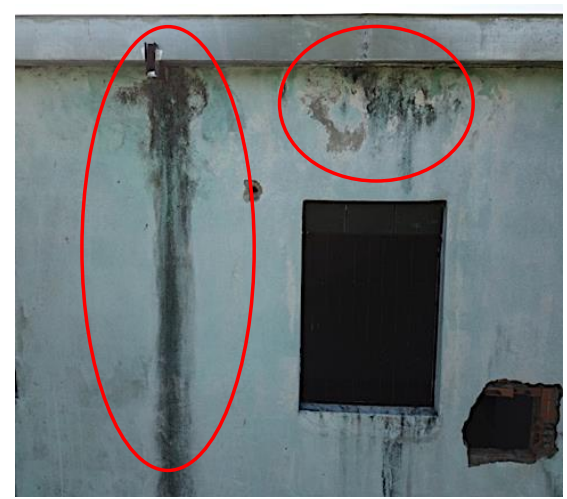

b)

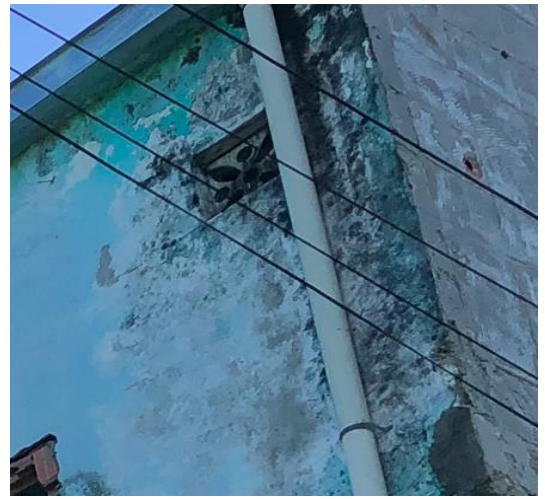

c)

Figura 9. Manifestações patológicas na Fachada Oeste: a) Manchas; b) Sistema de calha e as manchas; c) Sistema de calhas e condutor pluvial originando as manchas de umidade, bolor e descoloração da tinta.

\section{RESULTADOS}

Posteriormente à inspeção predial das fachadas da edificação e análise preliminar das patologias, foise realizado a matriz GUT. Através do Quadro 2, verifica-se os critérios de pontuação utilizados por Oliveira et al. (2016), para uma escolha segura de qual valor empregar nas variáveis de gravidade, urgência e tendência.

Quadro 2. Critérios de pontuação. Fonte: OLIVEIRA et al. (2016).

\begin{tabular}{|c|c|c|c|c|c|c|}
\hline \multirow{2}{*}{ GUT } & \multicolumn{5}{|c|}{ Pontos } & \multirow{2}{*}{ GxUxT } \\
\hline & 1 & 2 & 3 & 4 & 5 & \\
\hline Gravidade & $\begin{array}{l}\text { Problema } \\
\text { sem } \\
\text { gravidade }\end{array}$ & $\begin{array}{l}\text { Problema } \\
\text { com pouca } \\
\text { gravidade }\end{array}$ & $\begin{array}{l}\text { Problema } \\
\text { grave }\end{array}$ & $\begin{array}{l}\text { Problema } \\
\text { muito grave }\end{array}$ & $\begin{array}{c}\text { Problema } \\
\text { extremamente } \\
\text { grave }\end{array}$ & $\begin{array}{c}1 \times 2 \times 3 \times 4 \times 5 \\
=120\end{array}$ \\
\hline Urgência & $\begin{array}{c}\text { Situação } \\
\text { pode esperar }\end{array}$ & $\begin{array}{c}\text { Pouca } \\
\text { urgência } \\
\text { pode esperar } \\
\text { um pouco } \\
\end{array}$ & $\begin{array}{l}\text { Deve ser } \\
\text { resolvido o } \\
\text { mais rápido } \\
\text { possível }\end{array}$ & $\begin{array}{l}\text { Situação } \\
\text { urgente }\end{array}$ & $\begin{array}{c}\text { Intervenção } \\
\text { imediata }\end{array}$ & $\begin{array}{c}1 \times 2 \times 3 \times 4 \times 5 \\
=120\end{array}$ \\
\hline Tendência & $\begin{array}{l}\text { Situação não } \\
\text { irá mudar } \\
\text { caso nada } \\
\text { seja feito }\end{array}$ & $\begin{array}{l}\text { Situação irá } \\
\text { piorar a } \\
\text { longo prazo }\end{array}$ & $\begin{array}{l}\text { Situação irá } \\
\text { piorar a } \\
\text { médio prazo }\end{array}$ & $\begin{array}{c}\text { Situação irá } \\
\text { piorar a curto } \\
\text { prazo }\end{array}$ & $\begin{array}{c}\text { Situação vai } \\
\text { piorar } \\
\text { imediatamente, } \\
\text { caso nada seja } \\
\text { feito }\end{array}$ & $\begin{array}{c}1 \times 2 \times 3 \times 4 \times 5 \\
=120\end{array}$ \\
\hline
\end{tabular}

\subsection{Análise da Matriz GUT}

Através da matriz GUT realizada obteve-se as patologias de maior risco na edificação, e que consequentemente, devem ser prioritárias no momento de se realizar a reabilitação, conforme se visualiza no Quadro 3 a seguir. 
Quadro 3. Matriz GUT.

\begin{tabular}{|c|c|c|c|c|c|c|}
\hline MANIFESTAÇÃO PATOLÓGICA & $\begin{array}{l}\text { LOCAL DE } \\
\text { INCIDÊNCIA }\end{array}$ & $\mathbf{G}$ & $\mathbf{U}$ & $\mathbf{T}$ & $\begin{array}{l}\text { G X U } \\
\text { X T }\end{array}$ & $\begin{array}{l}\text { RANKING DE } \\
\text { PRIORIDADES }\end{array}$ \\
\hline $\begin{array}{l}\text { Descolamento/desplacamento das } \\
\text { placas cerâmicas }\end{array}$ & $1^{\circ} / 2^{\circ} / 3^{\circ} \mathrm{PAV}$ & 5 & 5 & 5 & 125 & $1^{\mathrm{o}}$ \\
\hline $\begin{array}{c}\text { Vegetação parasitária entre placas } \\
\text { cerâmicas }\end{array}$ & $3^{\circ} \mathrm{PAV}$ & 5 & 5 & 4 & 100 & $2^{\circ}$ \\
\hline Desprendimento do reboco da alvenaria & $1^{\circ} \mathrm{PAV}$ & 4 & 4 & 4 & 64 & $3^{\circ}$ \\
\hline Bolor na parede abaixo da caixa d'água & $3^{\circ} \mathrm{PAV}$ & 4 & 4 & 3 & 48 & $4^{\circ}$ \\
\hline Vegetação parasitária na marquise & $2^{\circ} \mathrm{PAV}$ & 4 & 4 & 3 & 48 & $4^{\circ}$ \\
\hline $\begin{array}{c}\text { Manchas de umidade e bolores no } \\
\text { suporte para ar condicionado }\end{array}$ & $2^{\circ}$ PAV & 4 & 4 & 3 & 48 & $4^{\circ}$ \\
\hline $\begin{array}{l}\text { Deterioração da esquadria metálica } \\
\text { com fissuras e destacamento do } \\
\text { revestimento }\end{array}$ & $3^{\circ} \mathrm{PAV}$ & 4 & 3 & 3 & 36 & $5^{\circ}$ \\
\hline $\begin{array}{c}\text { Bolores / fungos / manchas de umidade } \\
\text { nas primeiras fiadas da alvenaria }\end{array}$ & $1^{\circ} \mathrm{PAV}$ & 3 & 3 & 3 & 27 & $6^{\circ}$ \\
\hline $\begin{array}{l}\text { Manchas de umidade nas paredes } \\
\text { revestidas com tinta }\end{array}$ & $2^{\circ} / 3^{\circ} \mathrm{PAV}$ & 3 & 3 & 3 & 27 & $6^{\circ}$ \\
\hline Bolor nas paredes revestidas com tinta & $2^{\circ} / 3^{\circ} \mathrm{PAV}$ & 3 & 3 & 3 & 27 & $6^{\circ}$ \\
\hline $\begin{array}{c}\text { Bolor e sujidade no revestimento } \\
\text { cerâmico da marquise }\end{array}$ & $1^{\circ} \mathrm{PAV}$ & 3 & 3 & 3 & 27 & $6^{\circ}$ \\
\hline $\begin{array}{l}\text { Manchas de bolor e eflorescência no } \\
\text { revestimento promovido pelo sistema } \\
\text { de tubulação }\end{array}$ & $2^{\circ} \mathrm{PAV}$ & 3 & 3 & 3 & 27 & $6^{\circ}$ \\
\hline $\begin{array}{c}\text { Fissuras horizontais na amarração entre } \\
\text { laje e blocos cerâmicos }\end{array}$ & $3^{\circ} \mathrm{PAV}$ & 3 & 4 & 2 & 24 & $7^{\circ}$ \\
\hline $\begin{array}{l}\text { Fissuras entre parede de alvenaria e } \\
\text { viga de concreto armado }\end{array}$ & $1^{\circ} \mathrm{PAV}$ & 3 & 3 & 2 & 18 & $8^{\circ}$ \\
\hline $\begin{array}{c}\text { Eflorescência no revestimento de } \\
\text { pintura }\end{array}$ & $3^{\circ} \mathrm{PAV}$ & 3 & 2 & 3 & 18 & $8^{\circ}$ \\
\hline $\begin{array}{l}\text { Fissuras causadas por movimentações } \\
\text { higroscópicas }\end{array}$ & $2^{\circ} \mathrm{PAV}$ & 3 & 3 & 2 & 18 & $8^{\circ}$ \\
\hline Rejunte com microfissuras e sujidade & $1 \% / 2^{\circ} / 3^{\circ} \mathrm{PAV}$ & 3 & 2 & 2 & 12 & $9^{\circ}$ \\
\hline Corrosão das esquadrilhas metálicas & $1^{\circ} \mathrm{PAV}$ & 2 & 2 & 3 & 12 & $9^{\circ}$ \\
\hline $\begin{array}{c}\text { Sujidade nas paredes revestidas com } \\
\text { tinta } \\
\end{array}$ & $2^{\circ} / 3^{\circ} \mathrm{PAV}$ & 2 & 2 & 2 & 8 & $10^{\circ}$ \\
\hline $\begin{array}{c}\text { Sujidade nas placas cerâmicas } \\
\text { próximas à cobertura }\end{array}$ & $3^{\circ} \mathrm{PAV}$ & 2 & 2 & 2 & 8 & $10^{\circ}$ \\
\hline Fissuras mapeadas & $2^{\circ} \mathrm{PAV}$ & 2 & 2 & 1 & 4 & $11^{\circ}$ \\
\hline $\begin{array}{c}\text { Descoloração da tinta aplicada na } \\
\text { parede externa }\end{array}$ & $3^{\circ} \mathrm{PAV}$ & 2 & 2 & 1 & 4 & $11^{\circ}$ \\
\hline
\end{tabular}

A análise aponta que as manifestações patológicas com maior prioridade de intervenção são, respectivamente, as relacionadas com o descolamento ou desplacamento das placas cerâmicas 
localizada nos três pavimentos da edificação, a vegetação parasitária entre placas cerâmicas do terceiro pavimento e o desprendimento do reboco da alvenaria no primeiro pavimento.

\subsection{Diagnóstico das principais patologias}

Após a análise da Matriz GUT, foi observado que as três patologias com maior prioridade de resolução se correlacionavam, por mais que as causas para a manifestação destas não fossem as mesmas. Desta forma, optou-se por realizar o diagnóstico destas três patologias.

A patologia de maior risco do ranking de prioridades foi o descolamento ou desplacamento das placas cerâmicas que ocorreu de diferentes maneiras nas fachadas, abrangendo tanto o descolamento por ruptura adesiva quanto coesiva, conforme se visualiza na Figura 10.

A origem desta patologia foi na etapa de execução do revestimento cerâmico, que foi realizado cinco anos após a entrega da obra e sem a elaboração de um novo projeto de fachada. Através da Figura 10.b, pode-se visualizar que o assentamento das placas cerâmicas foram realizados acima da tinta do revestimento original e que o processo de apicoamento no revestimento estava incorreto. Além disto, constatou-se que parte das placas cerâmicas desplacadas não continham vestígios de argamassa colante (Figura 10.a), atestando falha durante a execução do serviço de assentamento do revestimento que culminou na falta de aderência entre os materiais.



a)

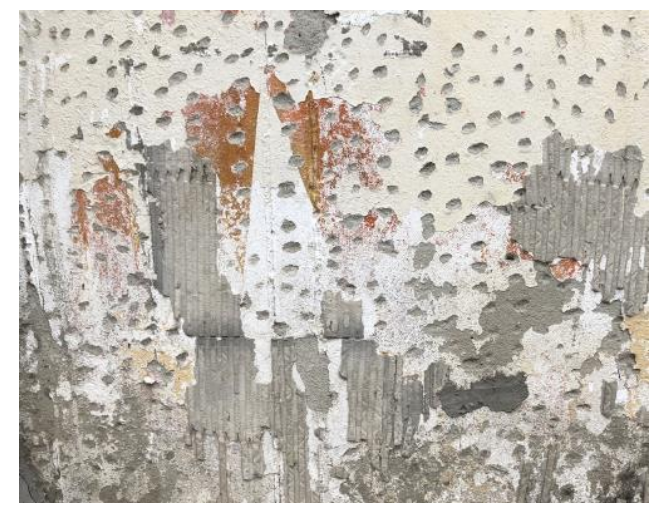

b)

Figura 10. Descolamento de placas cerâmicas: a) Placa cerâmica descolada; b) Parede externa com os resquícios da argamassa colante e do apicoamento realizado.

A segunda patologia com prioridade na resolução é a presença de vegetação parasitária entre as placas cerâmicas (Figura 5.b). Através da vistoria no local observou-se que a umidade presente na área desta patologia não se originava de causas internas à edificação, mas sim de agentes externos, como a chuva, devendo enfatizar que o clima da região é caracterizado por umidade elevada e alto índice pluviométrico. Desta forma, esta patologia se associa com o descolamento do revestimento, pois ambas tem como fator predominante as falhas na etapa de execução do assentamento do revestimento cerâmico. Não obstante, na Figura 5.b, verificou-se a presença de uma placa cerâmica quebrada e que os rejuntes das placas estavam com microfissuras e alta incidência de sujidade, sendo um favorecedor para a ocorrência desta patologia no local, por gerar permeabilidade no material e permitir a entrada de agentes agressivos.

Por fim, o desprendimento do reboco da alvenaria (Figura 3.d, Figura 11.a), localizado no primeiro pavimento, foi aferido como a terceira patologia de maior risco. Através da inspeção predial foi possível observar que o reboco não era consistente, visto que ao tocar no material ele se esfarelava com facilidade, indicando o excesso de finos em sua composição. Além deste indício, pôde-se observar a falta de homogeneidade na composição do reboco, visto que este apresentava elevada quantidade de torrões alaranjados, semelhantes a argila, conforme se visualiza na Figura 11.b e 11.c. 


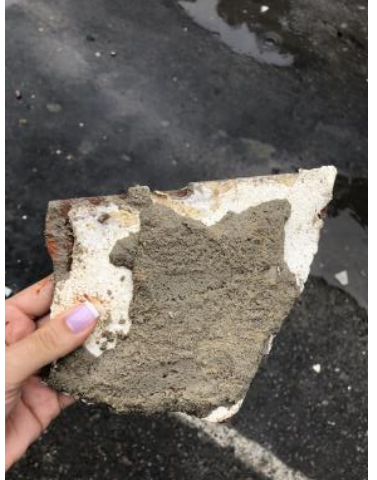

a)

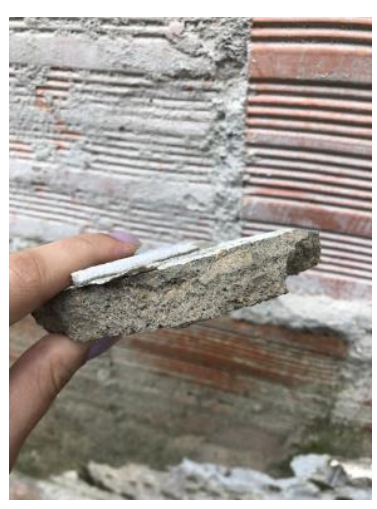

b)



c)

Figura 11. Desprendimento do reboco da alvenaria: a) Reboco desprendido; b) Torrões presente no reboco; c) Falta de uniformidade do reboco.

Buscando um correto diagnóstico desta patologia, optou-se pela realização de ensaio laboratorial, visando caracterizar mineralogicamente o composto alaranjado do reboco. Desta forma, a caracterização cristalográfica da amostra foi determinada por um ensaio de difração de raios-X (DRX), em um aparelho Bruker D2 Phaser, e através do programa X'Pert HighScore Plus identificou-se as fases minerais. Conforme o difratograma (Figura 12) abaixo, pôde-se verificar a presença de quartzo $\left(\mathrm{SiO}_{2}\right)$, principal composto da areia, anatase $\left(\mathrm{TiO}_{2}\right)$, um dos principais constituintes da tinta e o aluminossilicato $\left(\mathrm{Al}_{2} \mathrm{Si}_{2} \mathrm{O}_{5}(\mathrm{OH})_{4}\right)$ na amostra. $\mathrm{O}$ alumiossilicato, também conhecido como diquita, é um importante composto do calino e de outros minerais de argila. À vista disto, constatou-se a presença de argila na composição do reboco.

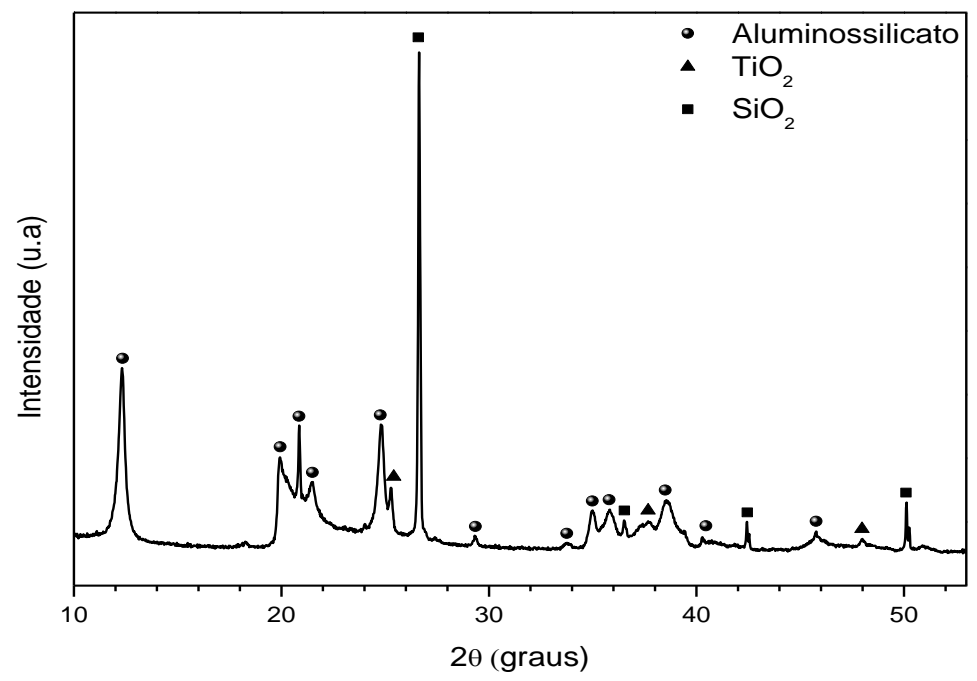

Figura 12. Difratograma apresentando as fases minerais identificadas da amostra.

Ainda para esta patologia, foi realizado o ensaio não destrutivo de percussão, possibilitando mapear as áreas com som cavo, que provavelmente estavam com problemas de aderência entre o reboco e a alvenaria. Desta forma, foi possível compreender a dimensão dos danos nas fachadas, e em paralelo a isto, concluiu-se que a origem da patologia estudada abrange as etapas de execução da obra e de escolha dos materiais utilizados. Não obstante, uma das causas para o surgimento desta anomalia é o clima da região, como já mencionado anteriormente.

Conforme Teixeira (2014), a presença de argila no reboco o torna mais poroso e, juntamente com um clima caracterizado por umidade elevada, este reboco favorece o desenvolvimento de microorganismos, fungos e contaminação biológica no revestimento. Comprova-se esta afirmação do autor através do 
estudo de caso da edificação, visto que a mesma apresenta alta incidência de bolores nas fachadas, juntamente com as patologias já relatadas acima. Mediante a isto, faz-se necessário analisar maneiras de reabilitar estas patologias.

\subsection{Procedimentos de reabilitação das principais patologias}

Na escolha dos procedimentos de reabilitação, deve-se ponderar que há inúmeras soluções e todas são igualmente apropriadas, eficazes e executáveis, se for realizado um estudo minuncioso quanto à sua execução e emprego dos materiais. De forma a selecionar a alternativa de intervenção mais adequada, deve-se buscar por embasamento teórico e argumentos concisos. Conforme Helene (2003), os principais fatores que devem ser analisados para escolha do tipo de reabilitação são: aspectos técnicos, econômicos, operacionais, arquitetônicos e ambientais.

Após o diagnóstico das patologias, optou-se inicialmente pela remoção do revestimento cerâmico, visto que o desplacamento destas peças gera um alto fator de risco para os transeuntes no local. Após isto, juntamente com o proprietário do imóvel, foi-se colocado em pauta todas as patologias identificadas e a necessidade de reabilitação, ressaltando a gravidade dos erros detectados no reboco, a falta de impermeabilização e manutenção predial.

Não obstante, através de autores, como o Mestre Miguel Teixeira, foi possível afirmar que argamassas de reboco com terra argilosa só devem ser aplicada em rebocos internos, pois quando aplicadas externamente não apresentam estabilidade necessária para desempenhar corretamente suas funções, visto que a argila é um material inerte que não apresenta um processo de endurecimento irreversível, podendo retomar sua plasticidade em contato com água.

Desta forma, por questões de segurança e com o intuito de melhorar o desempenho e funcionalidade do sistema construtivo, optou-se pela remoção de todo revestimento das fachadas, visto que a realização de reabilitação de cada patologia separadamente neste caso seria apenas um paliativo, se não alterar o reboco danificado.

Por fim, os procedimentos a serem realizados na edificação requerem, inicialmente, a execução de projetos de fachada contendo as especificações de impermeabilização, materiais a serem utilizados, vida útil e outros detalhamentos. Posteriormente a isto, efetuar a remoção dos revestimentos e executar o novo revestimento.

A execução do novo projeto de fachadas deve conter os procedimentos de execução abrangendo desde o preparo da base, com a etapa de limpeza, até o assentamento cerâmico. Ressaltando a necessidade de realizar os ensaios para verificar a aderência do reboco e das placas cerâmicas e o plano de manutenção predial, evitando futuros transtornos.

\subsection{Análise quantitativa das patologias}

Posteriormente à realização da metodologia proposta, as patologias identificadas no estudo de caso foram avaliadas mediante duas temáticas: origens patológicas e a incidência dos tipos de manifestações patológicas, conforme se visualiza, respectivamente, nos gráficos da Figura 13.
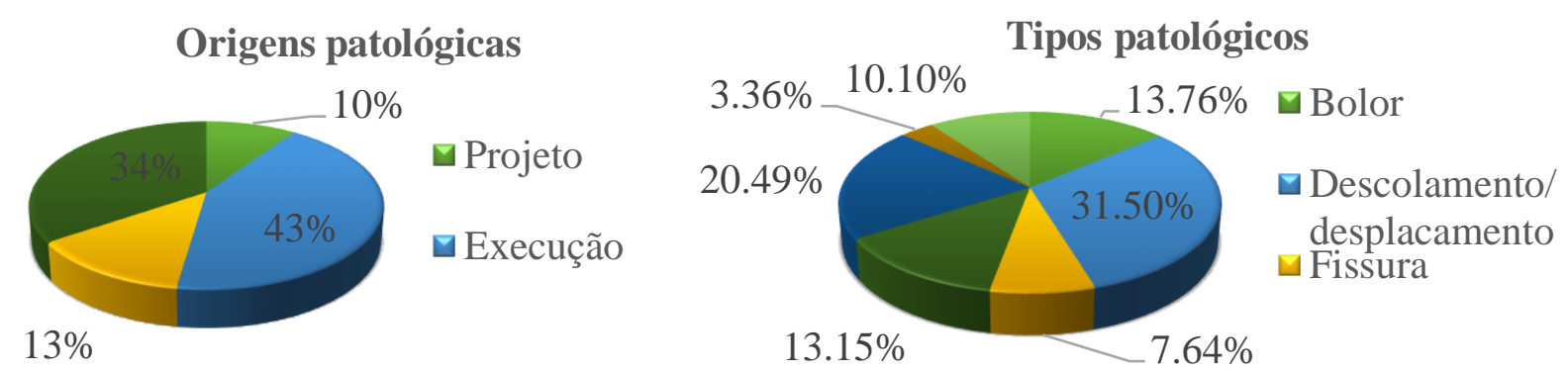

Figura 13. Gráficos relacionados as patologias identificadas nas fachadas da edificação: a) Origens patológicas; b) Tipos patológicos. 
Através do gráfico de origens patológicas, é possível aferir que as patologias identificadas nas fachadas da edificação são provenientes, principalmente, de falhas na etapa de execução (43\%) e falta ou utilização inadequada na etapa de uso/manutenção (34\%). Em relação ao gráfico dos tipos de manifestações patológicas é notório que o descolamento/desplacamento de placas cerâmicas $(31,50 \%)$ foram o tipo de anomalia mais incidente na edificação, seguido de manchas de sujidade $(20,49 \%)$ e bolor $(13,76 \%)$.

\section{CONCLUSÃO}

A fachada é um dos subsistemas mais importantes de uma edificação, sendo considerada a primeira e principal barreira de proteção. $\mathrm{O}$ fato da fachada estar externamente à edificação, faz com que a mesma receba maior atenção nos aspectos estéticos, do que nos aspectos funcionais, como se observa nas fachadas da edificação estudada. Todavia, este descaso com a funcionabilidade acarreta na manifestação de patologias, gerando a degradação da edificação.

Com o presente artigo, foi possível analisar as diversas patologias identificadas através de inspeção predial nas fachadas da edificação e constatou-se que a patologia com maior incidência foi $o$ descolamento/desplacamento de placas cerâmicas (31,5\%), devido principalmente aos erros de execução e falta de projeto. Em paralelo a isto, identificou-se que a maior parte das patologias se originaram de falhas executivas (43\%), seguido da ausência de manutenção predial (34\%).

Através da metodologia GUT foi possível analisar todas as anomalias e falhas existentes no estudo de caso, conforme as variáveis de gravidade, urgência e tendência, definindo uma ordem de prioridades para a reabilitação das mesmas, sendo comprovado a eficácia da ferramenta no estudo.

$\mathrm{O}$ atual estado de degradação das fachadas da edificação poderia ter sido minimizado através de um controle adequado durante a etapa de construção, obedecendo as boas técnicas construtivas e recomendações das normas vigentes, em conjunto com um planejamento de manutenção predial. Entretanto, atualmente a edificação se encontra em níveis elevados de deterioração e perda de desempenho e vida útil, sendo necessário medidas mais rigorosas, como a remoção de todo revestimento e aplicação de um novo.

Por fim, o estudo das manifestações patológicas das fachadas vinculado com a execução do diagnóstico e a proposta de reabilitação das principais anomalias, buscou beneficiar tanto para a empresa, proprietária do imóvel, quanto para os residentes, que poderão usufruir de uma edificação com maior qualidade e segurança.

\section{AGRADECIMENTOS}

A empresa BLR por ter consentido o estudo no seu imóvel e pelo suporte financeiro. Ao Instituto Federal de Educação, Ciência e Tecnologia do Amazonas pela disponibilização do acervo técnico e apoio às atividades de pesquisa desenvolvidas.

\section{REFERÊNCIAS}

Barbosa, A. S. (2013). Estudo Numérico-Computacional e Analítico do Choque Térmico em Fachadas de Edificações. 275 f. Dissertação (Mestrado em Estruturas e Construção Civil). Universidade de Brasília, Brasil.

BRASIL. Tribunal de Contas da União. (2013). Técnica de Análise de Problemas para Auditorias. Brasília: TCU, Segecex, Secretaria de Métodos Aplicados e Suporte à Auditoria (Seaud), 2013. Disponível em: <http://webcache.googleusercontent.com/search?q=cache:YZbgoc6Uj18J:portal.tcu.gov.br/lumis/port 
al/file/fileDownload.jsp\%3FfileId\%3D8A8182A258F9F3BD0158FE3DA8364C81+\&cd=2\&hl=ptBR $\& \mathrm{ct}=\mathrm{clnk} \& \mathrm{gl}=\mathrm{br} \& \mathrm{client}=$ safari $>$. Acesso em: 03 abr. 2018.

Fernandes, A. F. V. (2013). Do diagnóstico à conclusão da obra de edifícios de habitação - Estudo de Caso. 138 f. Dissertação (Mestrado em Engenharia Civil - Especialização em Construções). Universidade do Porto, Portugal.

Helene, P. R. L. (2003). Manual de reparo, proteção e reforço de estruturas de concreto. São Paulo. IBAPE - Instituto Brasileiro de Avaliações e Perícias de Engenharia. (2012). Norma de Inspeção Predial Nacional. São Paulo, Brasil. 18 p.

Ibraeng - Instituto Brasileiro de Auditoria de Engenharia. (2015). Inspeção Predial e Auditoria Técnica Predial. Ceará, Brasil. 18 p.

Júnior, G. J. F. (2017). Patologias em revestimentos de fachadas - Diagnóstico, prevenção e causas. 91 f. Trabalho de Conclusão de Curso (Especialização em Construção Civil). Universidade Federal de Minas Gerais, Brasil.

Kepner, C. H.; Tregoe, B. B. (1981). O administrador racional. São Paulo: Atlas. 238 p.

Lucinda, M. A. (2010). Qualidade - fundamentos e práticas para cursos de graduação. 1. ed. Rio de Janeiro: Brasport, Brasil. 180 p.

Junior, I. M.; Cierco, A. A.; Rocha, A. V.; Mota, E. B.; Leusin, S. (2010). Gestão da qualidade. 10. ed. Rio de janeiro: FGV, Brasil. 204 p.

Oliveira, L. L. M; Filho, F. S. P.; Madeira, M. J. A.; Almeida, E. M.; Sousa M. V. (2016). Aplicação da Matriz GUT em uma microempresa de assistência técnica. In: Anais do XVlll Encontro Internacional sobre Gestão Empresarial e Meio Ambiente - ENGEMA, São Paulo, Brasil. 12p.

Santos, M. J. B. O. (2017). Catalogação de patologias em fachada de edifícios residenciais de Brasília. 227 f. Dissertação (Mestrado em Estruturas e Construção Civil). Universidade de Brasília, Brasil.

Silva, M. N. B. (2014). Avaliação Quantitativa da Degradação e Vida Útil de Revestimento de Fachada - Aplicação ao Caso de Brasília/DF. 217 f. Tese (Doutorado em Estruturas e Construção Civil). Universidade de Brasília, Brasil.

Teixeira, M. A. N. N. (2014). Argamassas de reboco com terra: avaliação da suscetibilidade à contaminação biológica. 111 f. Tese Mestrado em Engenharia Civil - Perfil de Construção). Universidade Nova de Lisboa, Portugal.

Tristão, R. G. C. (2011). A importância das ações corretivas e ações preventivas nos sistemas de gestão da qualidade - Um estudo em empresas certificadas isso 9001 no estado do Rio de Janeiro. $91 \mathrm{f}$. Dissertação (Mestrado Profissional em Sistemas de Gestão). Universidade Federal Fluminense, Niterói, Rio de Janeiro, Brasil.

Tutikian, B.; Pacheco, M. (2013). Inspección, diagnóstico y prognóstico em la construcción civil. Boletim Técnico, ALCONPAT Internacional, Mérida - México. 15 p. 